\title{
Los imaginarios matacanes del castillo de Cornatel en El Señor de Bembibre de Gil y Carrasco. Estudio lexicográfico en torno a los términos matacán, matacaspas y sa[b]ratana
}

MARÍA ÁLIDA ARES ARES

Universidad de Trento mariaalida.aresares@unitn.it

\section{INTRODUCCIÓN}

El objetivo de este estudio es tratar de hacer luz sobre el término matacaspas que nos ha interesado por su aparición en la obra de Enrique Gil y Carrasco El Señor de Bembibre (1844) y que ha suscitado comprensibles dudas en los editores de la obra hasta hoy día, siendo enmendado con frecuencia por matacanes.

La enmienda aparece ya en la segunda edición, la de Joaquín del Pino y Fernando de la Vera e Isla (1883), y posteriormente en las de Jorge Campos (1954), Felicidad Buendía (1963), Arturo Souto Alabarce (1984) y, por último, en la de Ramón Carnicer (1992). El resto de editores conservan matacaspas, y así lo recoge también la edición más reciente de Biblioteca Gil y Carrasco del II Centenario dirigida por Valentín Carrera (2015).

El término se halla registrado en la base de datos CORDE (s. v. matacaspa), aunque solo está documentado en El Señor de Bembibre (1844) por lo que hasta hoy la voz constituiría un hápax, en el sentido en que emplea el término la literatura clásica para designar aquella palabra que sólo se documenta una vez en la literatura conservada.

\section{LOS MATACASPAS LITERARIOS DEL CASTILLO DE CORNATEL}

La acción de la obra se ubica en el siglo XIV en torno al tema de la extinción de la Orden de los Caballeros Templarios y el texto refleja la términología propia del lenguaje de época feudal. La voz matacaspas aparece en dos pasajes que pertenecen al capítulo 26, uno de los más significativos desde el punto de vista de la tensión narrativa, en el que tiene lugar el asalto al castillo de Cornatel por parte de las tropas del ambicioso conde de Lemos y la defensa del teniente templario de la fortaleza, el comendador Saldaña, entre cuyas gentes se encuentra D. Alvaro Yáñez, el Señor de Bembibre, protagonista de la novela. El episodio se concluye en el capítulo 28 con la derrota del de Lemos, que en un duelo con el comendador Saldaña cae despeñándose por el tremendo barranco que flanquea la fortaleza. A continuación transcribimos los dos párrafos del episodio que incluyen el término matacaspas: 
Aquellos desdichados mal armados, morían abrasados bajo una lluvia de plomo derretido, aceite y pez hirviendo que venía de la plataforma y de la cual salían también muchísimas flechas rodeadas de estopas alquitranadas y encendidas que no podían desprenderse, ni arrancarse sin quemarse las manos. Algunos quisieron retroceder, pero el extraordinario empuje que venía de afuera no sólo se lo estorbaba sino que vomitaba sin cesar sobre el puente nuevas víctimas. Los que estaban debajo de la arcada de la puerta, conociendo su peligro y creyéndose a cubierto por algunos instantes, menudeaban los golpes deseosos de terminar aquella horrenda escena, pero cuando más descuidados estaban, por unos agujeros, sin duda practicados de intento en las piedras, comenzó a llover sobre ellos aquel rocío infernal, y al querer retirarse, las piedras que caían por los matacaspas acabaron de estropearlos (Gil 1844: 259-260) ${ }^{1}$.

En el texto se nombran tres tipos de elementos arquitectónicos defensivos a la entrada de la fortaleza: la plataforma desde la que los sitiados les arrojan flechas encendidas y líquidos inflamables a los asaltantes; los agujeros practicados en el techo de la arcada [buheras] por los que les vertían plomo derretido, aceite y pez hirviendo; y los matacaspas, estructuras defensivas exteriores con agujeros por los que les arrojaban piedras desde arriba a los sitiadores. En el siguiente párrafo del mismo capítulo, aparecen otros términos técnicos del lenguaje de la arquitectura militar castrense (barbacana, armadura, hachas, portón) y de nuevo matacaspas:

[...] El conde [de Lemos] que con tanto ahogo y apretura se había visto embarazado en la barbacana, pudo desprenderse en aquel momento crítico, y arrojándose al puente para reanimar a los fugitivos y pasando por encima de los muertos y heridos sin hacer caso de las lluvias, piedras y aceite hirviendo que caían sobre su impenetrable armadura, llegó hasta la puerta con un cercano deudo suyo muy bien armado. Asieron allí las hachas de manos de dos muertos y comenzaron a descargar tan recios golpes que de arriba abajo se estremecía el portón a pesar de sus chapas de hierro. Entonces una enorme bola de granito bajando por uno de los matacaspas cayó a plomo sobre la cabeza de su pariente que al punto vino al suelo muerto, con el cuello y el cráneo rotos, viendo lo cual otros hidalgos de su casa que se habían quedado a la puerta de la barbacana, atravesaron el puente desolados, y a viva fuerza arrancaron de allí a su jefe (Gil 1844: 260-261).

De estos pasajes se infiere que los matacaspas son varios, que son grandes foros y que se encuentran en línea recta sobre el portón, ya que por ellos caen a plomo enormes bolas de granito sobre los que se acercan a él.

\section{INFLUENCIA DE IVANHOE EN EL SEÑOR DE BEMBIBRE}

Como ya señalaba Picoche (1972: 156), los capítulos del libro 26 a 28, donde se narra el sitio al castillo de Cornatel, beben de fuentes historiográficas, dramatúrgicas y novelescas. En lo que concierne al episodio del asalto a Cornatel, en la descripción de la batalla, repetidamente nos llegan ecos del asedio al castillo de Torquilstone de la novela de

${ }^{1}$ Citamos por Biblioteca Gil y Carrasco (2015): Obras Completas. Primeras ediciones [en línea] $<$ http://www.bibliotecagilycarrasco.com $>$. Las cursivas y negritas en las citas son nuestras y nos sirven para resaltar los términos que interesan particularmente para nuestro estudio. 
Walter Scott Ivanhoe (t. II, cap. VIII). Aún siendo la trama y los roles de los personajes diferentes, varios de los protagonistas de la novela de Gil recuerdan a los de Ivanhoe: así el templario Saldaña, el defensor del castillo de Cornatel, evoca al caballero templario normando Brian de Bois Guilbert y el montero Cosme Andrade a Robin Hood. El Conde de Lemos con su deudo se mueven en el escenario del asalto a Cornatel de modo similar a como lo hace el Caballero Negro con Cedric en el asalto a Torquilstone: avanzan por un puente de madera improvisado y se dirigen hacia el portón, que intentan abrir a hachazos.

Hay otros particulares narrativos de la táctica del asalto que no menciona Picoche que remedan también al de Ivanhoe, entre ellos el que para impedir que el conde de Lemos y su deudo abran la puerta del castillo los defensores arrojen por uno de los matacaspas la enorme bola de granito que le rompe el cráneo al deudo del conde. También en el capítulo VIII de la novela de Scott los sitiados, para impedir que el Caballero Negro y Cedric abran el portón, tratan de arrancar una enorme piedra del parapeto del baluarte para dejarla caer sobre las cabezas de los asaltantes; y están a punto de lograrlo cuando los gritos de alarma por el fuego del castillo los detiene. Ese particular de la piedra que representa el peligro que se cierne sobre los protagonistas en la novela de Scott consigue elevar la tensión narrativa del relato, creando un clímax de suspense muy efectivo, que creemos inspiró a Gil al escribir el particular del capítulo correspondiente de su libro.

Sin embargo, salvo barbacana, puente, portón y los términos que se refieren a armas defensivas, el resto no se corresponde con los de Ivanhoe, al menos en la traducción de José Joaquín de Mora de 1825, que sería la que con mayor probabilidad manejó Gil, y como alternativa la edición francesa de Defaucompret (Scott 1835), ya que conocía bien esa lengua. Transcribimos a continuación los pasajes de Ivanhoe en la edición inglesa seguidos de la traducción al español de Mora:

«Shame on ye all!» cried De Bracy to the soldiers around him; «do ye call yourselves cross-bowmen, and let these two dogs keep their station under the walls of the castle? -Heave over the coping stones from the battlement, and better may not be -Get pick-axe and levers, and down with that huge pinnacle» pointing to a heavy piece of stone-carved work that projected from the parapet [...]

The faithful Gurth indeed sprung forward on the planked bridge to warn Cedric of his impending fate, or to share it with him. But his warning would have come too late; the massive pinnacle already tottered, and De Bracy, Who still heaved at his task, would have accomplished it, had not the voice of the Templar sounded close in his heards: «-All is lost, De Bracy, the castle burns» (Scott 1831: 95).

Y el texto español de Mora (Scott 1825: 153):

«¿No os caéis muertos de vergüenza?», decía Bracy a los soldados que estaban sobre la puerta. «Os llamáis ballesteros, y permitís que esos dos bellacos se burlen de vosotros? Vengan aquí manos, y picas y palancas, y descarguémosles encima esa parte de la corniza». Dijo esto señalando a un grandísimo canto que sobresalía del muro, sirviendo de corniza entre este y las troneras [...].

El fiel Gurth se aventuró a pasar el puente para retirar a su amo de aquel inminente riesgo, o para morir a su lado. Pero ya resbalaba la piedra, y el celo de aquel excelente servidor hubiera sido infructuoso, y Bracy hubiera llevado a cabo su propósito si no hubiera oído en aquel instante la voz del Templario. 
«Todo se ha perdido, Bracy, gritó Brian. El castillo arde».

La traducción es imprecisa, Mora traduce huge pinnacle por «esa parte de la cornisa» y afirma que «ya resbalaba la piedra» mientras que el texto inglés solo dice the massive pinnacle already tottered, es decir, 'se tambaleaba'. Pero la versión española no solo es imprecisa en este capítulo, sino en general. Acerca del mérito de esta traducción Andrés Bello expresaba el siguiente juicio:

No aseguramos que el doctor Dryasdust [el editor] quedase completamente satisfecho con los equivalentes castellanos de algunas voces y frases relativas a ciertos usos de las edades caballerescas. Pero ¡qué diferencia entre el feudalismo español, modificado por la influencia arábiga $i$ el estado social que la conquista normanda produjo en Inglaterra! Los glosarios de ambos son por consiguiente diferentísimos, i no se puede verter el uno en el otro, si no aproximadamente o empleando circunlocuciones embarazosas. El traductor del Ivanhoe ha tenido razón en preferir el primer medio (1884: 40-41).

Bello tacha la traducción de Mora de aproximativa, subrayando las dificultades del traductor por la gran diferencia del léxico sectorial en las dos lenguas derivada de la influencia de la cultura arábiga en el de nuestra época feudal, y la normanda en la cultura inglesa.

El término inglés machicolation, correspondiente al español matacanes, no aparece en el pasaje correspondiente al asalto a la fortaleza del texto inglés, pero lo hemos hallado poco antes (Scott 1831: II, 12), ahí con la denominación machicolles, dentro de otro episodio también significativo de la novela inglesa y donde el autor hace una precisión metalingüística respecto a embrasures, señalando que machicolles era el término que se empleaba «en aquel entonces», refiriéndose al siglo XII en que está ambientada la novela, época que coincide con el regreso de los normandos de Tierra Santa de donde se dice que importaron a Inglaterra este elemento arquitectónico defensivo de las fortalezas (vid. Britton 1838: s. v. machilocation; v. q. Du Cange 1883-1887: s. v. machicolamentum).

Es un episodio en el que tiene lugar el intento de seducción por parte del caballero templario Brian de Bois de la judía Rebeca, que lo rechaza. Encolerizado, el templario se dispone a tomarla por la fuerza, pero Rebeca sube al parapeto almenado de un pequeño balcón, a sesenta pies de altura, y amenaza con arrojarse al vacío. Él, asustado, le promete que no la tocará y ella desciende del borde de la almena, quedándose junto a una de las embrasures o machicolles. El texto dice así:

«I will then trust thee», said Rebecca, «thus far»; and she descended from the verge of the battlement, but remained standing close by one of the embrasures, or «machicolles», as they were then called (Scott 1831: II, 12).

La traducción de Mora (Scott 1825: 16) es también aproximada e imprecisa:

«Cedo», dijo Rebeca, «pero no más que hasta aquí», y bajando del parapeto se apoyó en una de las almenas que lo guarecían. 
Traduce embrasures or machicolles por «almenas», cuando, al contrario, ambos términos se refieren a 'espacios o huecos' entre las almenas ${ }^{2}$ (vid. fig. 1 y 2$)^{3}$.

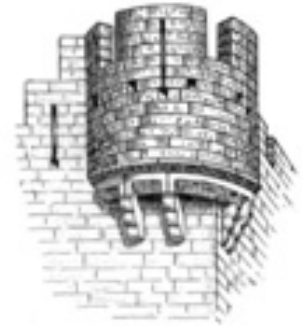

Fig. 1. Balcón amatacanado|

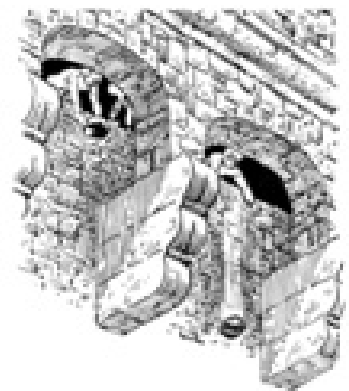

Fig. 2. Matacanes

En la traducción al francés de la misma época de Defaucompret (Scott 1835: 238) se distingue bien entre créneaux ('almenas') y embrasures o machicoulis ('troneras o matacanes'):

- Voici jusqu'où peut aller ma confiance en vous, dit Rebecca, en quittant les créneaux eten se serrant contre une des embrasures ou des machicoulis, comme on les appelait alors.

Michael Alexander (2011: 67) comenta el pasaje de Ivanhoe y el uso allí del término machicolles, haciendo notar que obedece a la intención del autor de proporcionar a los lectores de su época una imagen visual de como eran en el medioevo esas embrasures ('troneras') a las que se refiere, dándoles la forma de matacanes:

At the climax of Ivanhoe, Rebecca threatrens to throw herself from the battlements of Torquilstone rather than yield to the wicked advances of Brian de BoisGuilbert, Master of temple: «I will not trust thee, Templar», she says, «standing by one of the embrasures, or machicolles, as they were then called» (chapter 24). Scott put in these machicolles to authenticate, to inform us about machicolation, to furnish the imagination, to make the scene easier to visualize.

El término inglés machicolles, como señala el mismo Alexander, es equivalente a machicolation y en español matacanes (Villena 1988, s. v. matacán). Scott, algo antes del pasaje del intento de seducción de Rebeca donde aparece el término, había descrito la forma de ese espacio al que se accedía desde la habitación de la judía:

The single windows opened upon and embattled space surmounting the turret, which gave Rebecca, at first singht, some hopes of escaping; but she soon found

${ }^{2} C D E$ s. v. embrasures: «Opening in a wall or parapet, especially one through which a gun is fired».

${ }^{3}$ Fig. 1 tomada de Harris, ed. (1977); fig. 2 de Pearson Scott Foresman (Wikipedia, s. v. machicolation). 
it had no communication with any other part of the battlements, being an isolated bartizan or balcony, secured, as usual, by a parapet, with embrasures, at which a few archers might be stationed for defending the turret, and flanking with their shot the wall of the castle on that side (Scott 1831: II, 11).

La versión de Mora del pasaje es igualmente aproximativa, ya que deja sin traducir bartizan o balcony (vid. fig. 1), y se limita a hacer una traducción genérica: «puesto aislado [...] asegurado por un parapeto con almenas»:

La ventana daba a un espacio circular o azotea, la cual a primera vista le dio algunas esperanzas de poder escaparse por allí; más en breve, descubrió que esta parte del edificio no tenía comunicación con el resto de la fortaleza, sino que era un puesto aislado, asegurado, según era costumbre en aquellos tiempos, por un parapeto con almenas, en que podían colocarse algunos ballesteros, no solo para defender la torre, sino para flanquear el muro del castillo (Scott 1825: II, 7).

Como se puede apreciar, Scott describe y precisa con sinónimos el significado del término machicolles o machicoules que emplea, y opinamos que son posiblemente esos dos episodios de Ivanhoe, el del asalto con el particular de la piedra y el del intento de seducción de Rebeca donde aparece machicolles, los que llamaron la atención e inspiraron a Gil y Carrasco en su narración del asalto al portón.

Un testimonio elocuente del interés que suscitaba el término machicoules en Scott lo hallamos en otra obra suya, The Minstrelsy of the Scottish Border (1812: 78), donde hace un comentario acerca de este elemento defensivo de los castillos y define con más precisión la voz. Es en una nota a pie de página a propósito de battlemented tower, en la que precisa que las torres escocesas, a diferencia de las inglesas, suelen tener «unos intersticios entre el muro y el parapeto, llamados antiguamente machicoules, por los que se arrojaban piedras o dardos sobre los asaltantes»:

I have observed a difference in architecture betwixt the English and Scottish towers. The latter usually have upon the top a projecting battlement, with interstices, anciently called machicoules, betwixt the parapet and the wall, through which stones or darts might be hurled upon the assailants. This kind of fortification is less common on the south border.

Volviendo al cap. 26 de El Señor de Bembibre, vemos allí que Gil y Carrasco emplea matacaspas, al igual que Scott, refiriéndose a elementos defensivos de las puertas de las fortalezas, agujeros por los que se arrojan piedras y por los que podían bajar enormes bolas de granito. Como es sabido, los matacanes no solo se hallan sobre el portón de entrada, sino que también pueden encontrarse en bastiones, barbacanas y otros lugares de castillos e incluso en catedrales o iglesias. Respecto a la fidelidad de la descripción de la fortaleza de Cornatel en el episodio de Gil es revelador que en la descripción real que hace en Bosquejo de un viaje a una provincia del interior (El Sol, $47,11 / 03 / 1843$ ) no se mencionen barbacana, ni foso ni matacaspas, que, sin embargo, caracterizan el castillo en la novela (1844). Es probable, dada la presencia reiterada en la obra de Gil del castillo templario de Ponferrada, junto al que vivió siendo niño, que Gil en el capítulo del asalto fundiera en la narración elementos arquitectónicos de este castillo con los elementos naturales más escenográficos propios del enclave de Cornatel elevado en lo alto de un gran peñasco y rodeado de precipicios; sobre todo teniendo 
en cuenta el estado ruinoso de éste ya en en el XIX y la gran riqueza arquitectónica de la fortaleza de Ponferrada (vid. fig. 3) dotada de todos los elementos defensivos que se citan en la novela: foso, puente levadizo, barbacana y matacanes, sea en forma de balcón de piedra en medio del muro como el que está sobre la puerta del castillo viejo del s. XII, o bien como galerías corridas, parapetos amatacanados, a la entrada del castillo nuevo y coronando las torres de la barbacana del $\mathrm{s}$. XV.

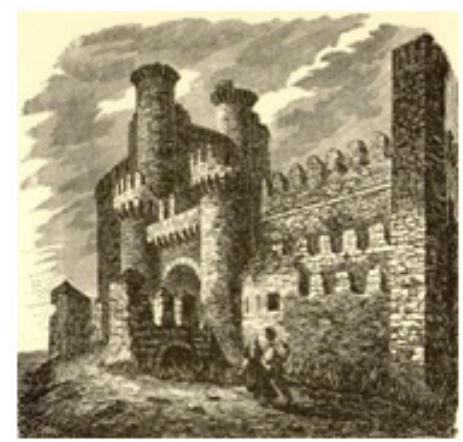

Fig. 3. Castillo templario Ponferrada

No cabe duda, por la paronimia de las voces matacán y matacaspa, y sobre todo por los datos que se proporcionan en el texto, que Gil emplea el término refiriéndose a matacán y, como hemos señalado, los editores Joaquín del Pino y Fernando de la Vera (1883), Jorge Campos (1954), Felicidad Buendía (1963), Arturo Souto Alabarce (1984) y Ramón Carnicer de (1992), lo enmendaron, al considerarlo una errata. Sin embargo, resulta improbable que si así fuera no lo hubiera advertido el tipógrafo Mellado cuando aparece dos veces a poca distancia en la misma página, y siendo un término desacostumbrado. Desde el punto de vista filológico es improbable además el aumento de grafemas -can >-caspa, así como la sustitución por parte del tipógrafo de un lexema comprensible por otro incomprensible en su contexto como -caspa. Esto nos lleva a pensar que su empleo ha sido consciente, a pesar de no estar documentada la voz en los diccionarios de uso ni en otras obras de la época y sí estarlo matacanes, como en la traducción de Nuestra Señora de París de Victor Hugo («[...] mejor que los matacanes de Lectoure», 1836: 122), por citar una de las muchas obras románticas que Gil sin duda conocía.

La primera hipótesis que nos hemos planteado ha sido que matacaspas fuera una voz dialectal usada en lugar de matacán, lo que era improbable pues no sería adecuado el uso de un dialectalismo en un contexto histórico medieval, pero no completamente descartable a priori dado el interés de Gil por recoger en sus escritos palabras dialectales del acerbo cultural leonés, cántabro y asturiano, como resulta en sus artículos costumbristas. Pero, como sospechábamos, la voz no se halla recogida ni en los diccionarios ni en los glosarios de voces asturianas ni leonesas que hemos consultado. La hipótesis más razonable, teniendo en cuenta el interés filológico y documental que muestra Gil en toda su obra, desde los poemas a los artículos costumbristas y descripciones de 
monumentos, es que se haya documentado bien sobre el léxico y haya tomado matacaspas y otros términos de algún tratado militar o glosario específico, lo que sería muy verosímil, dada su condición de segundo bibliotecario de la Biblioteca Nacional de Madrid de 1840 a 1844, periodo en el que escribió la novela.

Esta segunda hipótesis cobra relevancia desde el momento en que hemos podido averiguar que el término matacaspas no es exclusivo de la obra de Gil y Carrasco, ya que se halla también en un documento que se remonta a 1766 y en tratados posteriores de arquitectura colonial y su uso llega hasta nuestros días, empleado con el mismo valor de elemento defensivo de la puerta de una fortaleza.

\section{EL INFORME DE LAS FORTIFICACIONES DE CAMPECHE DE JUAN DE DIOS (1766)}

El texto más antiguo del que tenemos noticia en que se halla la voz matacaspa es Descripción de Campeche (México) por el ingeniero Juan de Dios González (1766), documento que se conserva en dos testimonios manuscritos que encontramos en tratados y ensayos de arquitectura militar: la monografía de Antonio Calderón Quijano (1984), que en el capítulo dedicado a Campeche comenta y transcribe el citado informe de Juan de Dios del manuscrito depositado en la Biblioteca del Palacio Real (signatura 2823; en adelante ms. BPR 2823), y el ensayo de Arroyo (2003) que transcribe el manuscrito conservado en el archivo del Servicio Histórico Militar de España (signatura 5-3: 9: 9; en adelante ms. SHM 5-3:9:9), del que existe también una copia en el Archivo General de Indias (denominado ms. AGI México 3157). En ambos testimonios aparece el término matacaspas, con variantes, y emparejado como sinónimo con saratana, también con diferentes variantes. Los pasajes en los que se encuentran los términos en el informe describen la Puerta de Tierra y la Puerta del Mar de la Fortaleza de Campeche. A continuación transcribimos tres citas donde aparece el término en el libro de Calderón [las negritas son nuestras]:

En la parte superior de la muralla tenía una especie de plaza de armas, con cuatro cañoneras a la plaza, e igual número a la campaña. Tenía una gran matas caspa o saratana para defensa con granadas. La puerta de jaby, grande, con fajas de hierro [...] (Calderón Quijano 1984: 280; describe la Puerta de Tierra).

Puerta de Mar y su muelle, se halla situado entre los dos dichos Baluartes y dista del primero 43 varas en el Plano de la Campaña, sin ninguna custodia, foso, puente ni rebellín, es de capacidad competente, encima tiene para defender la entrada con Granadas una Saratana o mata caspa a la izquierda un reducido Cuerpo de Guardia capaz de Cuatro o cinco soldados, que es la Guardia que tiene el Muelle, es corto y angosto y está casi arruinado, y necesita de preciso reparo (Calderón Quijano 1984: 400; describe la Puerta de Mar).

Puerta de Tierra se halla situada entre este Baluarte, y el antecedente de quien dista 226 varas. Al entrar por ellas hay una espaciosa bóveda muy clara, y capaz con dos departamentos a su derecha e izquierda, asimismo de bóveda que son cuerpo de Guardia, y Cuarto de oficial, sobre ellas, en lo superior de la muralla y plano horizontal forma dicha superficie una especie de Plaza de Armas con cuatro cañoneras a la plaza, igual número de dichos a la Campaña sobre la puerta con comunicación a la extensión de este terreno hay un curioso, y capaz masta caspa o saratana para defensa de ella con Granadas y fuego, con tres entradas, tiene 
disposición y caja para el descenso y ascenso de rastrillo. La puerta es de Jaby Grande, y capaz con sus fajas de hierro, delante de ellas está un rebellín de mampostería sobre el Plano horizontal que le guarnece una estacada por todo él, totalmente inútil, alrededor tiene un foso (a excepción de la parte de la puerta que está a un piso) reducido y su rastrillo, y puente levadizo el que está inútil y sin uso (Calderón Quijano 1984: 400-401; describe la Puerta de Tierra).

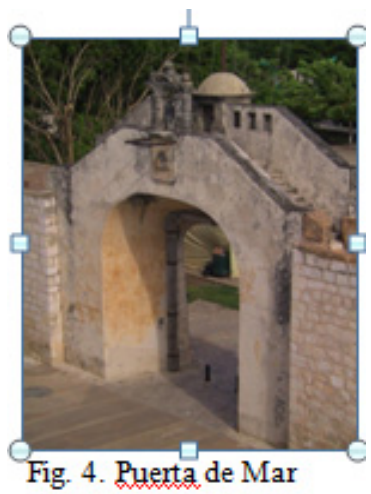

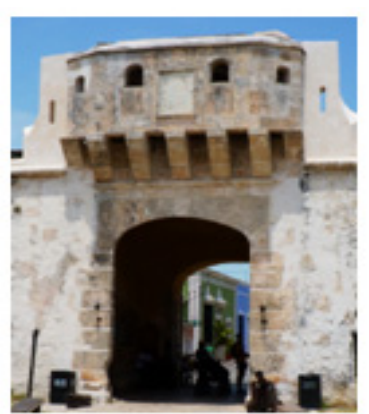

Fig. 5. Puerta de Tierra

Estas descripciones de ambas puertas las encontramos actualmente en la página web de Campeche, en la sección Turismo cultural - Arquitectura militar, que calca la descripción hecha por Juan de Dios, actualizando el lenguaje y las grafías y marcando con cursivas los términos matacaspa y saratana:

Esta puerta no tenía ninguna custodia, ni foso, ni puente, ni rebellín, y daba paso al muelle que era corto y angosto. Era de buena capacidad, y en la parte superior se encontraba una saratana o matacaspa. En su parte izquierda se encontraba un reducido cuerpo de guardia con capacidad para 4 o 5 soldados. En 1802, se reconstruyó un nuevo cuerpo de guardia que tenía 2 cuartos, uno para el comandante y el otro para la tropa. Poseía un corredor de $10 \mathrm{~m}$ x $6 \mathrm{~m}$. La actual Puerta de Mar es una reproducción de la original y fue construida en 1957 (página web de Turismo de Campeche, Puerta de Mar; fig. 4].

En la parte superior de la puerta podemos apreciar una matacaspa o saratana. Para la defensa de la puerta con granadas y fuego de artillería, tiene un espacio para el descenso y ascenso del rastrillo. La puerta es de madera de jabín, con fajas de hierro [...] (página web de Turismo de Campeche, Puerta de Tierra; fig. 5) .

La Puerta de Mar (fig. 4), realizada en 1957, aunque pretende ser una reproducción de la original está desprovista de matacán y la garita de la parte interna es un añadido que se ha traído de un bastión de las murallas adyacentes, puesto que no quedaba nada de la antigua puerta. Sin embargo la Puerta de Tierra (fig. 5) es la original y en la fotografía podemos observar el matacaspa.

${ }^{4}$ Las fotografias (fig. 4 y 5 ) que ilustran las descripciones y que muestran las puertas correspondientes las hemos tomado de la página web de Turismo Cultural de Campeche (URL: http://culturacampeche.com/turismocultural/monografias/campeche.html; consultado el 28/01/2015). 


\section{JUAN DE DiOS GONZÁLEZ}

El ingeniero Juan de Dios González inició su carrera militar en el Cuerpo de Ingenieros en 1742 y poco después fue destinado al Peñón de Gibraltar (Capel 1983: 215). En 1746 pasó a Alhucemas en la costa norte africana, donde levantó el plano de la costa fronteriza y del presidio en ella edificado, y en 1753 llegó a Nueva España en sustitución de Alonso González de Villamar. En su nuevo destino realizó trabajos de cartografía de la Ciudadela de San Benito, de la que luego efectuaría la descripción. El año 1755 realizó tres planos generales de la Provincia de Yucatán y poco después, en mayo del mismo año, pasó a la Plaza de Campeche, donde efectuó el reconocimiento de las fortificaciones, de los edificios reales y el proyecto de las obras que se debían realizar para alojar al Batallón de Infantería de Castilla. Campeche fue el territorio que quedó más detalladamente reflejado en sus informes. En 1778 fue ascendido a Comandante de Ingenieros e Ingeniero Principal de la provincia de Yucatán y en 1783 se le nombró Comandante interino de Campeche y Teniente del Rey.

Hemos querido dejar constancia de su formación y la importancia de su labor en arquitectura militar para mostrar la relevancia del testimonio que documenta el empleo del término matacaspas. El informe de Juan de Dios ha sido el más completo que se ha realizado de las fortificaciones de Campeche y la fuente de todas las descripciones posteriores de la fortaleza. San Francisco de Campeche se encontraba rodeado de una muralla de forma hexagonal con ocho baluartes, murallas y cortinas, y con cuatro puertas de acceso a la plaza, entre las que destacan la de Mar y la de Tierra. Hemos hallado abundante bibliografía moderna de arquitectura colonial, además de los citados estudios de Calderón y Arroyo, donde recurren a los términos saratana y matacaspa al describir la Puerta del Mar y Puerta de Tierra de Campeche, y todas las descripciones parten del informe del ingeniero Juan de Dios de 1766.

La misión de Juan de Dios González era, por una parte, informar en general sobre la situación y el comercio en la línea costera de la Península de Yucatán; por otra, inspeccionar el estado en que se encontraban desde el punto de vista militar las fortificaciones de las tres principales ciudades de la provincia: Mérida, Campeche y Bacalar. Respecto a Campeche, se mostraba preocupado por las condiciones de defensa del puerto y de la ciudad y es por ello por lo que elabora un informe tan detallado.

\section{LOS TESTIMONIOS MANUSCRITOS DEL INFORME DE JUAN DE DIOS}

De los dos testimonios manuscritos que conocemos, el ms. S.H.M. 5-3: 9: 9 que transcribe Mercedes Arroyo (2003) lleva el título

Reconocimiento de la provincia de Yucatán y parte de la costa de onduras. desde punta de Castilla viajando por el oeste y cavo de Catoch hasta la ysla de Tris o presidio del Carmen en que se manifiesta los siguientes cabos, ensenadas, rios y puertos: el número de vixias y los parajes que deven fortificarse; recintos de la costa y relación exacta de la Ciudadela de San Benito desde Mérida, Plaza de 
Campeche, Fuerte de Bacalar y Presidio del Carmen, sus Fuerzas y Artillería montada y estado de estas Fortificaciones.

Mientras que el ms. B.P.R. 2823 que transcribe Calderón Quijano (1984) $)^{5}$ se titula

Reconocimiento de la provincia de Yucatán y parte de la costa de Honduras, en que se manifiestan los surgideros, cabos, ensenadas, etc., que deben fortificarse y relación exacta de la ciudadela de San Benito de Mérida, plaza de Campeche, fuerte de Bacalar y presidio del Carmen, por el ingeniero don Juan de Dios González, año 1766.

En su estudio, Arroyo no cita o desconoce el ms. B.P.R. 2823 y considera erróneamente S.H.M. el manuscrito original. Para la transcripción del informe afirma que ha respetado la ortografía y que ha desarrollado las abreviaturas e introducido algunos signos de puntuación «para la correcta comprensión del documento». Transcribimos a continuación los párrafos de este manuscrito relativos a la Puerta de Mar y Puerta de Tierra, para compararlos luego con los correspondientes del ms. BPR 2823:

Puerta del Mar y su Muelle se halla situada entre los dos Baluartes y dista del primero 43 varas en el plano de la Campaña sin ninguna custodia, foso Puente ni revellin, es de capacidad competente, encima tiene para defender la entrada con granaderos una santana ó mata carpa á la Yzquda un reducido Cuerpo de Guardia capaz de 4 ó 5 soldados que es la guardia que tiene: el Muelle es corto y angosto, esta quasi arruinado y necesita de preciso reparo [transcripción S.H.M. 53: 9: 9, Puerta de Mar].

Observamos las diferencias, que marcamos en negrita y cursiva, respecto al manuscrito BPR 2823:

Puerta de Mar y su muelle, se halla situado entre los dos dichos Baluartes y dista del primero 43 varas en el Plano de la Campaña, sin ninguna custodia, foso, puente ni rebellin, es de capacidad competente, encima tiene para defender la entrada con Granadas una Saratana o mata caspa a la izquierda un reducido Cuerpo de Guardia capaz de Cuatro o cinco soldados, que es la Guardia que tiene el Muelle, es corto y angosto y está casi arruinado, y necesita de preciso reparo.

Comparando los dos textos se puede advertir que el texto S.H.M.5-3:9:9 que transcribe Arroyo es posterior. Desde el título observamos que ha habido algunas supresiones, como surgideros, y numerosas adiciones, y en los pasajes transcritos observamos también que el ms. SHM ha sido modificado «corrigiendo» el original, como muestra la concordancia con muelle que cambia la terminación del adjetivo situado < situada; el uso del adjetivo referencial dichos $<$ dos; la corrección de la minúscula en lo que el copista interpreta como denominación de lugar Plano < plano; y al contrario, puente < Puente; la corrección de la ortografía en revellin $<$ rebellin; la sustitución del objeto por el sujeto en granaderos $<$ Granadas; la transformación de un término desconocido por otro conocido que observamos en santana $<$ Saratana, así como en mata carpa $<$ mata caspa; también

${ }^{5}$ Calderón Quijano cita también la copia «Reconocimiento y estado de la provincia de Yucatán, por Juan de Dios González, ingeniero, en Campeche», 18-II-766 (A.G.I. México 3157), que se correspondería con la de SHM 5-3:9:9. 
las abreviaturas Izquda $<$ izquierda; o la transformación del número por la palabra $4<$ Cuatro; y los cambios de sentido de una frase: guardia que tiene $<$ Guardia que tiene el Muelle; y, por último, la enmienda con el uso del arcaísmo quasi < casi. Esto último podría dar indicios de la proveniencia del copista, ya que las formas alternadas quasi/cuasi perviven en el XVI (por ejemplo en Farsas o quasi comedias, de Lucas Fernández), pero en el s. XVIII había monoptongado, si bien la forma quasi pervive en el español de América. Lo mismo sucede si comparamos las transcripciones de ambos por lo que se refiere a la Puerta de Tierra, donde en el ms. S.H.M. se lee:

Puerta de Tierra [...] sobre la puerta con comunicación á la extension de este terreno ay un curioso y capaz cuarto carpa o Zaratana para defensa de ella con granadas y fuego, con tres entradas, tiene disposicion y casa para el dezenso y ascenso de rastrillo. La puerta es de clabos grande y capaz con sus fajas de fierro.

Mientras que en el ms. B.P.R. 2823:

[Puerta de Tierra]... sobre la puerta con comunicación a la extensión de este terreno hay un curioso, y capaz masta caspa o saratana para defensa de ella con Granadas y fuego, con tres entradas, tiene disposición y caja para el descenso y ascenso de rastrillo. La puerta es de Jaby Grande, y capaz con sus fajas de hierro.

También aquí interviene la mano del copista en el ms. S.H.M. llevando a cabo sustituciones y alteraciones gráficas: cuarto carpa $<$ masta caspa; zaratana $<$ saratana; ajustando la grafía de las mayúsculas o modernizándola: granadas < Granadas; dezenso $>$ descenso; en los errores de interpretación: casa < caja; y en los cambios de puntuación. Un particular significativo es la interpretación errónea de puerta de Jaby como puerta de clabos; el jabí es un árbol de América, de madera muy dura, tan compacta que apenas puede cortarse con el hacha (DRAE, s. v.).

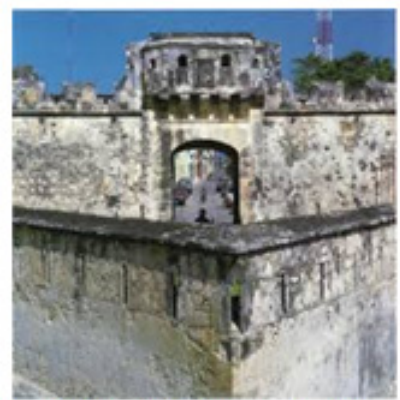

Fig. 6. Revellin Puerta de Tierral

Todo ello nos lleva a considerar más antiguo el testimonio ms. B.P.R. 2823, y por consiguiente los términos saratana y mata caspa, que se repiten sea para la puerta de Mar que la de Tierra. En cuanto a la -s- de masta, que aparece en la descripción de la puerta de Tierra creemos que podría ser una epéntesis debida a la cercanía y atracción de la $s$ de caspa. 


\section{LA TRANSMISIÓN E INTERPRETACIÓN SEMÁNTICA DEL INFORME}

Terradas, en su discurso de ingreso a la RAE (1946), advierte cómo el rápido crecimiento de esta ciencia, sobre todo en lo que se refiere a ciertos periodos de la historia, obliga a introducir conceptos nuevos cuya expresión requiere nombres adecuados, que comienzan siendo vacilantes, con variantes, sinónimos, denominaciones aproximativas y neologismos, y paulatinamente se irán consolidando después de un periodo de fluctuación en el que se unifican criterios y pareceres, hasta adquirir su precisa forma y significación. Estos cambios y vacilaciones afectan a los testimonios manuscritos, como hemos observado en S.H.M. 5-3:9:9 y B.P.R. 2823, donde las dos voces han dado lugar a diversas interpretaciones, y debido a ello partes del documento original han sufrido modificaciones léxicográficas y también de sentido, sea con la sustitución: cuarto carpa < mata carpa; la unión de diversas cadenas grafemáticas: matacaspa < mata caspa; o bien por la restitución de cadenas incompletas: caspa < mata caspa, tal como sucede en los documentos que vamos a ver a continuación.

Si bien, como hemos dicho, en los tratados actuales en que se describen las dos puertas de Campeche parecen haberse fijado las grafías saratana y matacaspa, hemos hallado dos excepciones, dos casos en que se suprimen elementos de la cadena y se les da una interpretación semántica diversa que consideramos de interés, porque confirman que ambos términos han constituido un enigma hasta el día de hoy que confiamos poder esclarecer. La primera excepción la encontramos en el tratado de Ramón Gutiérrez (2005: 91-93), en el capítulo «Campeche y sus fortificaciones (México)», donde el autor, que recoge la literatura precedente sobre el tema, explica de este modo el significado de los dos términos del informe de Juan de Dios referidos a la Puerta de Tierra (vid. fig. 5) y que él transcribe como caspa y saratana:

Posteriormente, en 1732 se cerrarían las puertas de mar (San Francisco y San Román), más fáciles de ser tomadas, y se abrió la puerta de Tierra con una suerte de barbacana (llamada caspa o saratana), un cuerpo de guardia abovedado, revellín para protegerla y foso.

La segunda excepción e interpretación terminológica la encontramos en el estudio monográfico, Piedras ante el mar de José Enrique Ortiz Lanz (1996: 61-63), también aquí en la descripción correspondiente a la Puerta de Tierra ${ }^{6}$ :

Conserva integra sus cañoneras, sus casamatas (casas donde se guardaba la pólvora), troneras, almacenes y defensas constituidas por una escarpa destacada en forma de triangulo, tiene también un foso de unos $4 \mathrm{~m}$. de ancho y unos 3 de profundidad que la rodeaba. En este foso no había agua, sino estacas cruzadas con puntas filosas. Tiene un conjunto de rendijas en la parte superior que es la saratana.

Ambos tratadistas, ante la dificultad de encontrar otras referencias y definiciones de los términos empleados por Juan de Dios, mata caspa y saratana, suprimen una parte

${ }^{6}$ La fotografía que se muestra en la fig. 6 ha sido tomada de la página web de Turismo Cultural de Campeche (vid. n. 5) 
de la cadena grafemática (mata) y ofrecen una interpretación de caspa forzada, basada en observación del objeto de la descripción, ya que la Puerta de Tierra tiene delante en efecto un revellín (vid. fig. 6) ${ }^{7}$, que sería lo que Ramón Gutiérrez considera «una especie de barbacana», y ese revellín tiene forma triangular de ahí que Ortiz Lanz lo denomine escarpa ${ }^{8}$. Respecto a saratana, Ramón Gutiérrez lo considera sinónimo de caspa, como en el texto de Juan de Dios; mientras que Ortíz Lanz considera que con él se refiere a las aspilleras ${ }^{9}$ que se encuentran en el revellín. Pero estas explicaciones de ambos no servirían para la Puerta de Mar que, como afirma Juan de Dios en su descripción, no tenía «ninguna custodia, foso, puente ni rebellín» y, sin embargo, también tenía matacaspa o saratana como la Puerta de Tierra, por lo que la interpretación de ambos no es atendible. Además, como podemos observar la Puerta de Tierra que es la que todavía se conserva, tiene en la parte superior un matacán, por tanto creemos que la palabra hace referencia a este elemento defensivo.

\section{ESTUDIO DE LOS TÉRMINOS MATACÁN, MATACASPAS, SARTANA Y SUS VARIANTES Y ACEPCIONES}

Para intentar resolver el enigma de forma e interpretación que plantean las voces matacaspas y saratana en los textos aportados hemos llevado a cabo un pequeño estudio lexicográfico de las tres voces. Estudiaremos en primer lugar el término matacán y su sinónimo matacaspa, sea quebrado, como lo emplea Juan de Dios, sea unificado, como en otros documentos derivados y en El Señor de Bembibre, y en segundo lugar la voz saratana (fem. sing.) del ms. B.P.R 2823 de Juan de Dios (1766), por estar usada allí como sinónimo. Atenderemos tanto al significado y etimología de cada una de ellas en los diccionarios y glosarios específicos, como a su uso en los tratados de arquitectura militar u otros textos históricos.

De las varientes que hemos hallado de matacaspa y saratana en los testimonios manuscritos del informe de Juan de Dios y en los tratados y estudios posteriores derivados, consideramos mata carpa y cuarto carpa del ms. S.H.M. 5-3:9:9 modificaciones del original, y escarpa y caspa errores de interpretación en los textos de Ramón Gutiérrez y Ortiz Lanz, ya que remiten a elementos defensivos diversos. Por otra parte, en Zaratana y Santana del ms. S. H. M. 5-3:9:9 sospechamos una lectio facilior de los términos originales, y en masta caspa del ms. B.P.R. de Calderón una epéntesis en la primera palabra por atracción de la $-s$ - debido a similitud fonética de ambos miembros.

\subsection{Matacán}

Respecto al significado de la voz en el léxico militar, el DRAE (2014: s. v.) lo define como: «Obra voladiza en lo alto de un muro, de una torre o de una puerta fortificada, con parapeto y con suelo aspillerado, para observar y hostilizar al enemigo». Hay

\footnotetext{
${ }^{7}$ Revellin. Mil. «Obra exterior que cubre la cortina de un fuerte y la defiende» (DRAE 2014: s. v.)

${ }^{8}$ Escarpa. Mil. «Plano inclinado que forma la muralla del cuerpo principal de una plaza, desde el cordón hasta el foso y contraescarpa» (DRAE 2014: s. v.); V. q. Sánchez Orense (2012: s. v. escarpa).

${ }^{9}$ Aspillera. Mil. «Abertura larga y estrecha en un muro para disparar por ella» (DRAE 2014: s. v.)
} 
que subrayar, sin embargo, que la Academia no recoge esta acepción del término hasta la edición de 1899, y allí con la definición: «Voladizo de piedra a manera de cajón sin cubierta ni suelo, adherido a una ventana del muro en las fortificaciones antiguas y principalmente sobre la puerta de entrada, para hostilizar a quien se arrimase a ella». Otras acepciones diversas del término que recogía el diccionario académico en la misma ed. de 1899 y que se hallaban ya en las ediciones precedentes eran las siguientes:

Especie de liebre grande y zancuda, que ha sido ya corrida de los perros ${ }^{10}$. Llamóse assí porque los cansa y molesta. Latín. Lepus grandis Composición venenosa para matar los perros. Llaman tambien assí al guijarro o piedra que se les tira. Latín. Offa venefica. Lapis. Metafóricamente se llama qualquier trabajo molesto, pesado y fastidioso. Latín. Improbus labor (DA-1734).

En cuanto a los sinónimos, la Academia registra cadahalso antes de matacán, pero extrañamente no lo hace hasta la ed. de 1822 y de una forma genérica, como: «Fortificación o baluarte hecho de madera. Propugnaculum ligneum». La voz ladronera tampoco se recoge hasta la ed. de 1852: «Fort. matacanes», pero todavía no se encuentra matacán como lema, ya que no aparece hasta 1889 .

Los matacanes conservados en España se remontan al s. XIV, pero están documentados ya en las ilustraciones de las Cantigas alfonsíes de mediados del XIII, por lo que su uso es anterior. Tienen como precedente los cadalsos y buhardas y los mocharabis árabes, especie de galerías corridas sobre ménsulas que coronaban las torres y murallas. Como elemento defensivo se consideran una aportación arquitectónica de los normandos importada al regreso de las cruzadas a imitación de las que se encontraban en las fortalezas árabes, como el balcón de matacanes de la puerta de Bad al-Nasr de las murallas de El Cairo (Menéndez Pidal 1986; García Cuadrado 1993).

Respecto a su origen, Du Cange (1883-1887) registra MACHICOLAMENTUM (1346) «specie munimenti oppidorum» y MACHACOLLADURA (1382) «Gall. Machecoulis. Pergulæ species in superiori turrium parte, unde in oppugnatores lapides aliaque projiciebantur». Villena (1985: 112) después de enumerar la denominación en las diversas lenguas (al. maschikulis, Gusslochreihe; cat. matacà, corsera; fr. machicoulis, ant. machicol (ie), machecoulis; ingl. machicolation, machicolis; it. caditoia; port. mata$c \hat{o} o$ ), afirma que las voces en inglés y alemán provienen del francés medieval MACHICOULIS (vid. Le Duc 1863: VI, 196-213, s. v. machicoulis) y este del latín medieval MACHICOLAMENTUM, otorgándole el significado etimológico que daba Godefroy (18811902) de 'briser le cou' derivado de macher y cou > 'romper el cuello' (vid. Godefroy 1881-1902 : s. v. machicoulis), una falsa etimología y una acepción posterior, como la del español mata y cán > 'mata-perros' en el sentido de 'infieles'.

Si consideramos la etimología latina, MACHINA posee el significado de 'ingenio, artefacto’ (Sallustio: oppidum machinis expugnare, ‘expugnar la fortaleza con las máqui-

\footnotetext{
${ }^{10}$ La acepción de matacanes como «liebres corridas por los perros» se suele apoyar en la interpretación de Juan Ruiz, Libro de buen amor, c. 1220 «e muchos [perros] nocherniegos que saltan matacanes» (ed. Blecua 1992). Si bien otros editores como Jacques Joset (1974) interpretan matacanes o ladroneras en el sentido propio, ya que si fueran liebres — como dice Joset — no se comprendería nocherniegos.
} 
nas de guerra') y Isidoro (Etimologías, Lib. 19, 8,2) le da el de 'andamio' (vid. infra massacan). Y colamentum, 'filtro o coladero', proveniente de COLARE 'verter, deslizar, colar' (Du Cange 1883-1887, s. v. colare), por lo que el significado etimológico es el de andamio o construcción elevada de defensa que servía para arrojar piedras, flechas o líquidos sobre los atacantes, es decir, los antiguos matacanes llamados buhardas o bubardas, especie de andamios sujetos en el tejado que se podían mover o deslizar, tal como se describe Almirante en el Diccionario militar (1969, s. v. buharda). No obstante, la interpretación etimológica 'briser le cou' en francés o 'mata perros' en español, sigue apareciendo en muchos diccionarios hasta hoy día.

En cuanto a la voz esp. matacán, documentada en s. XIV (aunque ya se encuentran en las miniaturas de las Cantigas de Alfonso X el Sabio), y que los diccionarios hacen derivar también del francés machicoulis - aunque paradójicamente le otorguen distinto significado- en nuestra opinión posee un origen etimológico diverso, como mostraremos a continuación.

En el Universal vocabulario de Alfonso de Palencia (1490), s. v. matta: «Matta vulgariter cella dicta fuit». Como se puede comprobar en el mismo Vocabulario, s. v. cella: «Cella se dice que cubra y esconda a nosotros o a alguna cosa dentro de sy» $(<$ Cella dicta q. nos vel aliquid occulte cellet). Mata sería pues 'lugar que cubre o esconde', derivado del lat. CELARE 'esconder/-se, ocultar/-se', como en italiano. Con este significado de matta 'pequeña cámara', Cristóbal de las Casas en Vocabulario de las dos lenguas toscana y castellana (1570), traduce también la voz toscana homófona, casamatta —que hace referencia a otro tipo de defensa de las fortalezas, pero que a veces ha llegado a confundirse con matacán - por choza. Y Covarrubias en Tesoro (1674) la define: «casa encubierta», y dice que «es una tronera que está en lo baxo del mur de la fortaleza a raíz del foso, que puesta en ella una pieça de artillería impide el poderle cegar, porque va rayendo la superficie del agua, y de la tierra». Y en cuanto a matta Covarrubias: «llamose mata por ser baxa». En $D C E C H$ de Corominas y Pascual, encontramos ya su significado actual s. v. casamata: «Bóveda muy resistente para instalar una o más piezas de artillería (1536, del it. casamatta (1520)», y en cuanto a su origen, al hacerlo derivar del italiano MATTO, ofrece una falsa etimología: «parece tratarse de casa matta, propiamente 'loca' (del griego mataios), con el valor de 'falsa, impropia, en el sentido de «algo que parece una casa» (v. q. Sánchez Orense 2012: s. v. casamata). En realidad casamata, teniendo en cuenta su etimología, sería un término redundante, ya que al significado etimológico de CASA ('choza', 'pequeña casa') se le añade el de matta (<CELLA) 'habitáculo, lugar que cubre o esconde' y que, como afirmaba Covarrubias, originalmente se construía en la base de la escarpa externa, para defender el foso de la fortaleza, y posteriormente se construyeron por todo el perímetro defensivo de la fortificación, e incluso en los niveles superiores ${ }^{11}$, pasando luego, con las transformaciones sucesivas, a convertirse en la trinchera actual.

${ }^{11}$ Vid. Istituto Italiano dei Castelli, sezione Campania, Breve glossario de termini difensivi, Napoli, s. v. casamatta. Consultable en URL: http://www.castcampania.it/glossario.html; Almirante (1969), s. v. casa, afirma que no es cierto que las primeras casamatte las hubiera construido Durero, como se venía afirmando en tratados anteriores como en De' Marchi (1810). 
Por lo que se refiere al sufijo de matacán, el mismo Covarrubias, s. v. can: «Canes en los edificios son unas cabeças, o de maderos o de piedra, que suelen sobre ellos sentar unas vigas largas, y armar los suelos sobre ellas [...] Y llamáronse todos estos canes porque ordinariamente están labrados en ellos unas cabeças de perros».

El DRAE (2014) recoge el testimonio de Covarrubias y registra esta definición, $s$. $v$. can: «Cabeza de una viga del techo interior, que carga en el muro y sobresale al exterior, sosteniendo la corona de la cornisa. Modillón».

Leonardo de Villena (1971) considera también los canes como contrafuertes: «Coronamiento de las murallas o torres formando una obra destacada que ensancha la base del adarve y deja unas aspilleras (agujeros cuadrados o alargados) en dirección vertical, cada una entre dos canes o contrafuertes. Destinado a la defensa vertical, en sustitución de los vulnerables cadalsos».

Es probable que $C A N-C A N I S$, referido a las vigas de sostén de los antiguos cadalsos y matacanes, y más tarde a los contrafuertes o modillones en piedra, fuera, como afirman Covarrubias, DRAE y Villena entre otros autores, el origen etimológico de la desinencia de la voz castellana, y no 'perros' en el sentido de 'infieles', aunque este fuera el sentido que adquirió popularmente más tarde y que recogen gran parte de diccionarios; sin embargo, se trataría de una etimología inexacta, ya que la desinencia de las voces machicoulis, machicolamen, derivan de coulisse (del francés COULIS) y éste como dijimos del lat. COLARE, 'colar, verter, discurrir', y COULIS posee el significado de 'canalillos, canaladuras' por donde se arrojan las piedras u otros materiales' (Ramée 1868: s. v. machicoulis). En apoyo de esta interpretación etimológica se sumarían las voces mazgal y mazgali en turco que tienen el significado en el lenguaje militar de 'matacán, tronera o saetera' y el de 'sumidero, alcantarilla'. Y también en italiano el término caditoia designa sea a matacán que a desaguaderos o alcantarillas (vid. Trecanni 2015: s. v. caditoia).

Volviendo a la voz en esp. matacán, hay que señalar además la variante con desinencia femenina y en plural, matacanas, que encontramos con frecuencia, y que aparece ya en 1862 con el descriptor casas mata-canas ${ }^{12}$, donde se observa que ya se ha perdido la consciencia del significado etimológico de mata 'recinto, habitáculo' de modo que se superpone al término el sustantivo casa que significa lo mismo y, por otro lado, se empiezan ya a confundir entre sí las voces casamata y matacanas.

Por último, quisiéramos reseñar también por su interés para subrayar la estrecha vinculación entre las palabras homófonas dentro de un área específica, como en este caso de la arquitectura, la voz massacàn o masacàn, con la acepción de 'albañil', generalmente de baja categoría, que encontramos en genovés, ligur y siciliano, la cual los diccionarios consideran una derivación semántica extensiva y peyorativa de masacán 'piedra, guijarro', en el sentido de 'quien trabaja con las piedras ${ }^{13}$. El origen etimológico sería del latín bárbaro MACIO ( $<$ MATTIO, MACHIO) que encontramos en Isidoro,

\footnotetext{
${ }^{12}$ Franquelo (1862: 28), al describir el Castillo de Carabineros de Málaga, dice: «Además llevaba casas mata-canas».

${ }^{13}$ Como sucede también en italiano con la voz muratore 'albañil' proveniente de muro 'pared' (Treccani 2015. URL: www. Treccani.it).
} 
Etimologías, Lib. 19, 8,2: «Maciones dicti a machinis in quibus insistunt propter altitudinem parietum» ('Los albañiles [maciones] reciben su nombre de los andamios [machinae] en los que suben debido a la altura de las paredes'; Du Cange (1883-1887), $s$. v. macio), y del que proviene el francés maçon, declinado mascon y mascan, y el provenzal massacan del cual a su vez deriva el italiano massacan y mazzacan con el mismo significado de 'albañil' (Rocca 1871). La voz it. mazzacano se haya documentada en Savona ya en 1187, en Atti di Arnaldo Scriva, donde se cita a Henrico mazzacano, considerado en ese documento como maestro de albañilería que trabaja artísticamente con piedras y cemento, derivado del maçon francés.

En los glosarios provenzales (Avril 1839: s. v. massacan) la voz posee también el significado de «relleno de piedras y escombros para las crujías». En el Dictionnaire provençal-français (Honnorat 1817), s. v. massacan se ofrecen las dos acepciones que posee hasta hoy en día: «Blocage, petits caillous plats, que le maçons emploient pour remplir les vides que les grosses pierres laissent entre ellas ou qu'ils noyent dans le mortier», y figuradamente: "Mauvais maçon, mauvais ouvrier». Pero hay que señalar, como muestra de las confusiones etimológicas que han tenido lugar con palabras homófonas, que Honnorat remite a Achard (1785) para la etimología de la palabra, y este la hacía derivar de un MASSAR forma abreviada por AMASSAR, 'matar', y de CAN, 'perro', con lo que el significado etimológico que le da Achard y sus seguidores sería, como el de matacán, o sea, 'mata perros'. Y Honnorat se pregunta con signo de interrogación: «ipiedra que se tira a los perros?» (1817 : s. v. massacan).

Para terminar hay que decir que mata, en el sentido de 'refugio fortificado' lo encontramos también en numerosos topónimos, como el del castillo de la Mata o de Casa Mata, que adopta la semblanza de un gran fortín, y en poblaciones como Matacán-es (México), Matacães en Portugal. Nos atrevemos a sugerir también un posible origen común con el término motta, voz probablemente prerromana con el significado de 'elevación del terreno, montículo, colina' que podía ser natural o construido artificialmente y en el que solía haber una torre defensiva y que está muy presente en la toponomástica italiana (vid. Treccani 2015: s. v. motta), y que con frecuencia también en español y en francés hace referencia a torreones defensivos como el castillo de la Mota o Mota del Marqués en Valladolid y los diversos chateaux o torreones franceses denominados la Motte.

\subsection{Matacaspa}

Sobre el término matacaspa (1844) que hallamos en Gil y Carrasco y mata caspa en Juan de Dios (1766), por lo que concierne al origen, hemos llevado a cabo una labor de rastreo en los diccionarios recogidos en el Nuevo Tesoro Lexicográfico de la RAE (2015) y en los glosarios y tratados de terminología militar citados, y hemos llegado a las siguientes conclusiones que sometemos a la consideración y autoridad de los especialistas: en primer lugar creemos que se puede afirmar que en realidad se trata de una voz compuesta, mata y caspa y en su acepción de 'estructura defensiva' ambas serían sinónimos que denominan un artefacto o ingenio llamado en latín cattus del que derivan en primer lugar las voces gata y gato. Almirante en su Diccionario militar (1969: s. v. gata) la define: «aparato o máquina de sitio o aproche; galería cubierta, vinea, testudo, pluteo, manta, tortuga; aparato cubridor del ariete, según la mayoría de los 
autores» (vid. fig. 7) ${ }^{14}$. Esta máquina, prosigue Almirante, «en el bajo latín se llamó cattus, gattus pero también capsa, causia, gosia, gucia, gussa. En francés tuvo también numerosas variantes: caschaz, chat, chastiax, chast, chateil, etc.» Y Du Cange afirma que de cata deriva la voz italiana catafalco y la francesa èchaufaud, 'andamio' (18831887: s. v. catus $^{2}$ ). Gata y gato sería pues una voz genérica para designar diversos tipos de 'machinas o ingenios defensivos' y que desempeña un papel relevante en la poliorcética de la Edad Media. S. Isidoro define así el término en Etimologías, lib. 12: «Gatas y manteletes. Son ciertas machinas de guerra para combatir lugares fuertes». Du Cange cita a Vegetio, lib. 4, cap. 15: «Vineas dixerunt veteres quas nunc militari barbaroque usu Cattos vocant» (1883-1887: s. v. catus $\left.^{2}\right)$. Almirante señala que fue en la edición de la obra de Steuvechius (1583) cuando los cattos y el derivado gatas se convirtieron en CAUSIA, por confusión etimológica, sostiene Almirante, ya que San Isidoro dice que cattum proviene de CAPTURA $A^{15} y$ de aquí deriva también CAPSA. Sobre la forma y objeto de esta 'máquina' o 'ingenio', existe igual incertidumbre, prosigue Almirante: «Algunos suponen que era el toleno, otros, 'torre de asalto con ariete', pero la mayor parte de los lexicógrafos 'galería cubridora', vinea, plúteo». Según el Diccionario de la lengua castellana de la Academia (1726-1739), más conocido como Diccionario de Autoridades (en adelante $D A$ ), s. v. gata: «Un género de cobertizos de madera recia para defensa de los minadores en las murallas. Llamáronse también Mantas en los antiguos. En latín, pluteus, vinea».
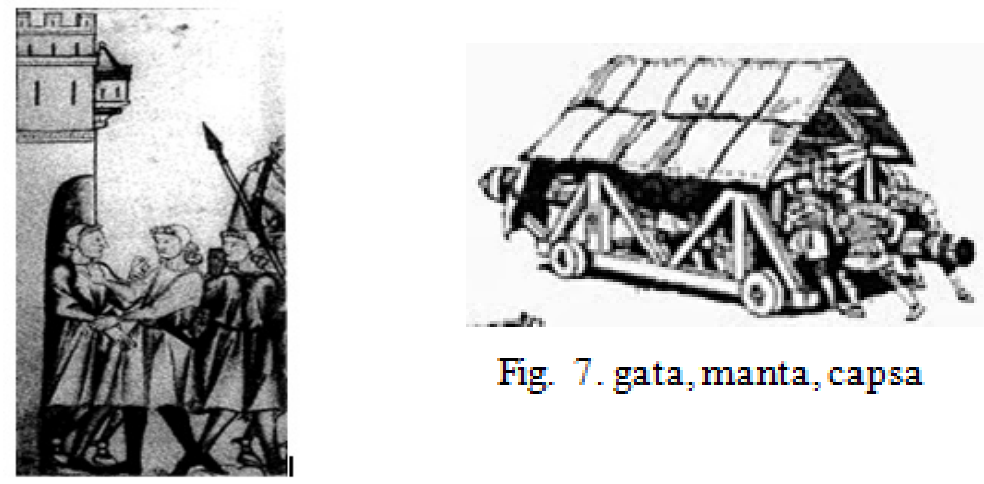

Fig. 7. gata, manta, capsa

Fig. 6. Matacán Cantiga $13 \mathrm{~b}$.

Así pues creemos que el término matacaspa ha derivado de la confusión y unión de dos sinónimos en lenguaje militar MANTAS y CAPSA.

${ }^{14}$ Tomada de: http://www.romanoimpero.com/2015/02/macchine-da-guerra.html.

15 «Bueno es recordar que las dificultades intrínsecas de entender a los antiguos, se hacen de todo punto insuperables con los embrollos, más bien que aclaraciones, de los copistas, intérpretes y comentadores. Puede presumirse el interés etimológico que habrá despertado entre los eruditos esta palabra realmente extraña. Uno sospecha que cattus, quasi cautus, se dijo por lo sagaz y listo que es el gato; otro dice cattum, quasi acutum, perspicaz, porque el gato ve de noche; otro va a buscar una Gattide o Gatta reina de Siria, Rochefort al árabe, chas o chaz» (Almirante 1969: s. v. gata). 
Por otra parte, la homofonía de mata derivada de MATTA 'receptáculo, cubierta' y MANTA, también 'cubierta', ha podido generar la confusión tardía entre matacanes/ matacanas y mata caspas, aunque en su origen denominaran dos elementos defensivos diversos y contrapuestos.

MANTAS con esta acepción lo encontramos ya en Nebrija (1495) «Manta para combatir. Testudo-inis» y Covarrubias (1611), s. v. manta: «Cierta maquina béllica que cubre a los que han acometido a escalar el muro de los enemigos y esta defiende que no les ofendan las piedras, la pez, y resina, alquitrán, y otras cosas que les arrojan de lo alto. Manta se dijo de MANTO (vid. Vegencium, lib. 4, cap.14)».

La voz CAUSIA, aparece documentada en Zerolo $(1895$, s. v. causia): «Nombre que se daba a la máquina militar llamada también gata». En el DRAE (1914) s. v. caspia: «quizá del mismo origen que caspa». De capsa a caspa se habría producido una metátesis lingüística del grupo - $p s$ - en -sp-. En Bolletino della società pavese di storia $p a-$ tria entre el mobiliario se documenta capsa y capsa armata, una especie de arca con cajones y provista de una espaldera que servía también como banco para sentarse (Repossi 1901: 22) que sería postulable como origen del término casamatta italiano. Así se van entrelazando los términos: matacan, massacan, mata caspa, casamata, que a veces se confunden al formar parte de un mismo campo semántico de la arquitectura militar y tener algunos rasgos comunes.

Por tanto creemos que cattus como cubierta (capsa, manta) usada como 'ingenio o máquina de guerra', sería el origen de mata caspa, de especial modo en el sentido que lo usa Juan de Dios, como refugio defensivo, fortín para protegerse, y que conserva también muchas de las características de forma y funcionalidad de los matacanes medievales (vid. fig. 5), de ahí que se fundan los nombres, aunque estas construcciones más modernas están dotadas de aspilleras y de armamento, generalmente culebrinas, también llamadas sabratanas o cerbatanas, de las que trataremos a continuación.

Otra hipótesis que tuvimos en cuenta referida a matacaspas, solo en el caso de que la voz se hallara así documentada ya en textos medievales, era que caspa se hubiera formado por influencia del árabe qaṣba 'fortaleza o fortificación' pronunciación dialectal del árabe clásico qașaba 'casba' (Treccani 2015: s. v. casba), por ensordecimiento de la -b- oclusiva. En español se conserva la voz árabe en topónimos como Casba de Huesca, Casba de Jaca y en Caspe (Zaragoza) que aparece documentado en fuentes andalusíes como Qasb, Qsp o Qasp). Creemos que la influencia árabe es posible dado que los matacanes, como apuntábamos arriba, se hallan documentados en Las Cantigas de Alfonso X como defensas de castillos árabes (fig. 6), y se cree que sea un elemento arquitectónico defensivo proveniente del Mediterráneo oriental, ya que se encuentra también en la puerta Bad al Nasr de las murallas del Cairo que se remontan al s. XI (García Cuadrado 1993: 221 y ss.; vid. fig. 6). El término estaría relacionado, como sostiene García Cuadrado (1993) con los mocharabis < MUSHERABIYA de los palacios árabes, especie de galerías corridas sobre mensulas que coronaban las torres o murallas (González Simancas 1925: 119-120, apud. García Cuadrado 1993: 228). 


\subsection{Saratana}

Por lo que concierne al término saratana y sus variantes, el DRAE (2014) registra zaratán (Del ár. hisp. SARATÁN, y este del ár. clás. SARATTANN, literalmente, 'cangrejo, cáncer'. Med. «Cáncer de los pechos en la mujer. m. coloq. Seg. y Vall. Cordelería, taller u obrador donde se hacen cordeles, que también lleva el nombre de atarazana» Vergara Martín (1921: 84) registra la voz zaratán: «Taller u obrador destinado a la cordelería», y la variante zaratana, precisando: «Así lo llamaban en Segovia, Cuéllar, Sepúlveda y otras localidades donde hacían cordeles y cuerdas de cáñamo». Pero no obstante la homonimia, no creemos que pueda ser el origen de la voz saratana o zaratana en el sentido de mata caspas, estructura defensiva, que tendría en el contexto en que el término es usado por Juan de Dios.

La voz saratana no la hemos hallado así escrita en los diccionarios consultados ni tampoco en los tratados específicos con el significado que se le atribuye en el informe. Hemos hallado topónimos como Sartana, Sarzana, Ceratanum o Cerratana y gentilicios como Saracena que podrían haber sido su origen si fuera adjetivo y se aplicara en el sentido de 'un tipo de construcción propia de un lugar', como torre saracena, referido a las torres que se construyeron en el s. XVI a lo largo de las costas del Reino de Nápoles por orden de Pedro de Toledo para avistar las naves sarracenas y prevenir sus incursiones. También se denomina saracena a un tipo de plancha con clavos suspendida en lo alto de las puertas de entrada a una fortaleza, que en caso de explosión caía cerrando la entrada (Prosperi 1744: 72).

Sin embargo, tratándose de un sustantivo y considerando la época y el contexto en el que está utilizado el término en el informe de Juan de Dios, hemos descartado la hipótesis de los gentilicios y nos hemos centrado en los términos relacionados con la defensa de las fortalezas, yendo a buscar en los tratados militares y en los relatos históricos de asedios de ciudades fortificadas. Así, en Colección de documentos inéditos para la historia de España de Sancho Rayón (1848: 398), en referencia a la batalla de Toro de 1476, se lee: «E ordenadas sus batallas puso en la delantera dellas sus sebratanas é espingarderos», refiriéndose con el último término a los arcabuceros que manejan espingardas, arcabuces o cañones de artillería, como son las sebratanas, por otro nombre culebrinas. Y en vol. 106: 263, donde se habla sobre los preparativos para el asedio a Granada, en pág. 263: «[...] llevar seis medias lombardas y diez robaduquines, e otras diez sebratanas con sus piedras, e mucha pólvora, e mil espingarderos y mil e quinientos paveses $[\ldots]$...

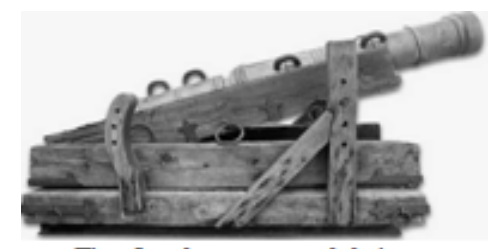

Fig. 8 cebratana, culebrina 
El origen de sebratana sería el término derivado del árabe ZARBATÁNA, árabe clásico SABATĀNA, del cual provienen el port. sarabatana, cat. sarbatana, fr. sarbacane, el it. cerbotana y esp. cebratana, cerbatana y también la variante sebratana, que encontramos en los textos citados. Du Cange registra la voz del griego vulgar ZARABOTANA con el significado genérico: «Machinae jaculatoriae species» Chalcoon. Lib. 7. Y DA (1726-1739) s. v. cerbatana: «Especie de culebrina, de mui poco calibre, que por ser casi de ningún provecho no se usa ya en buenas fundiciones (Tosc. Tom. 5. P1.458). «Lat. Fistula ferrea jaculatoria». Si bien en las ediciones posteriores la denominación latina se modifica: Lat. Tormenti bellici genus». La culebrina, que también se denominó moyana, se nombra como invento reciente en las crónicas de Pedro Mártir de Anglería, que refiere que Hernán Cortés envió desde méxico al emperador Carlos V una culebrina de oro (vid. Mártir de Anglería 1944: lib. 11, cap. 2, 625).

Así pues, tanto por el contexto en el que se usa la voz saratana en la obra de Juan de Dios, como por la homonimia con sebratana, somos del parecer que el término usado por Juan de Dios, saratana, se refiera a este tipo de cañón y, por extensión, al lugar de avanzadilla en el que se colocaban dichas armas de artillería para la defensa de las plazas, que en el caso de las puertas de Campeche era además un matacán. Y no se puede descartar que exista otro ms. anterior a los dos testimonios conservados del informe de Juan de Dios donde la voz sea sebratana o sarbatana.

\section{CONCLUSIÓN}

Nuestro objetivo al iniciar el estudio era el de averiguar la propiedad del uso de la voz matacaspas en el cap. 26 de El Señor de Bembibre, para lo cual hemos estudiado el contexto y acudido a sus fuentes literarias y hemos recogido documentación lexicográfica acerca del uso del término en la literatura especializada, en base a lo cual podemos afirmar que la aparición en la obra de Gil y Carrasco de la voz estaría legitimada y no constituye un hápax como hasta ahora se venía considerando ya que el término se halla también documentado, con el significado de matacán, en el informe Descripción de Campeche del ingeniero Juan de Dios González de 1766, así como en diversos tratados y ensayos posteriores, perviviendo hasta la actualidad, si bien con uso localizado y restringido. En segundo lugar hemos querido arrojar luz sobre el origen, la etimología, las variantes y acepciones que han ido cobrando diversas voces relacionadas de la arquitectura medieval defensiva que giran en torno al término matacán como matacaspas y saratana.

Esperamos que este estudio pueda contribuir a subrayar el interés que encierra la cuestión terminológica relacionada con la arquitectura e ingeniería militar y la construcción de las fortificaciones desde la Edad Media hasta la Era Moderna con la creación de nuevas voces a medida que surgen necesidades defensivas; los préstamos e influencias entre ellas; los matices diversos de significado en las diferentes lenguas, y su transformación, pervivencia o desaparición debida a la evolución tecnológica.

Por último, nuestro mayor deseo sería el haber podido mostrar que el estudio de antiguas voces desusadas y semiperdidas, como matacaspas, saratanas, apenas documentadas, contribuye a ampliar el conocimiento sobre la historia y evolución diacrónica del lenguaje, el mecanismo de creación de palabras nuevas, y las influencias que ha habido 
entre las diferentes lenguas en la creación del léxico sectorial de las artes y ciencias, y muy especialmente en el referido a las fortificaciones y a la construcción, esperando que pueda servir para ampliar la documentación en la base de datos CORDE de la $R A E$.

\section{REFERENCIAS BIBLIOGRÁFICAS}

ACHARD, Claude-François (1785): Le vocabulaire Français-Provençal et ProvençalFrançais, Marseille, Mossy, 2 vols.

ALEXANDER, Michael (2011): «Architecture in Historical Fiction. A Historical and Comparative Study», en Rumiko Handa y James Potter, eds., Conjuring the Real: The Role of Architecture in Eighteenth and Nineteenth Century Fiction, Lincoln, University of Nebraska Press, pp. 67-86.

AlmiRANTE, José (1969): Diccionario militar, etimológico, histórico y tecnológico con dos vocabularios francés y alemán, Madrid, Imprenta y Litografia del Depósito de la Guerra.

ARroyo, Mercedes (2003): «El reconocimiento de la Península de Yucatán realizado por el ingeniero militar Juán de Dios González (1766)», Biblio 3W, Revista bibliográfica de Geografia y Ciencias sociales (Serie documental de la Geo Crítica), viII/475 [Consultable en URL: http://www.ub.edu/geocrit/b3w-475.htm].

AVRIL, Joseph Toussaint (1839): Dictionnaire provençal-français, Paris, Cartier.

BAZZANA, André, ed. (1985): Castrum 3. Guerre, fortification et habitat dans le monde méditerranéen au Moyen Age, Madrid, Publications de la Casa de Velázquez, fasc. XII; Collection de l'École française de Rome, t. 105 (Actes du Colloque organisé par la Casa de Velazquez et l'École française de Rome, Madrid, 24-27 novembre 1985).

Bello, Andrés (1884): Obras completas, Vol. 7, Opúsculos literarios y crítico, Santiago de Chile, Pedro G. Ramírez.

BIERBRAUER, Volker y Carlo Guido MOR (1986): Romani e Germani nell'arco alpino: (secoli VI-VIII), Bologna, Il Mulino.

BRITTON, John (1838): A Dictionary of the Architecture and Archaeology of the Middle Age, London, Logman.

CAlderón QuiJano, José Antonio (1968): Las murallas de Campeche, Campeche, Gobierno del Estado de Campeche.

CALDERÓN QUiJANO, José Antonio (1984): Historia de las fortificaciones en Nueva España, Madrid, Gobierno del Estado de Veracruz-CSIC-Escuela de Estudios Hispanoamericanos de Sevilla.

CAPEL, Horacio et al. (1983): Los ingenieros militares en España, siglo XVIII, Barcelona, Universidad de Barcelona.

Collins DisCovery ENCYClOPEDIA (CDE) (2005): Glasgow, Harper Collins Publishers.

CoROMInAS, Joan y José Antonio PASCUAL (1980-1991): Diccionario crítico etimológico castellano e hispánico (DCECH), Madrid, Gredos.

CORTADA Y SAlA, Juan (1841): El templario y la villana: crónica del s. XIV, Barcelona, Brusi.

DE LAS CASAS, Cristóbal (1570): Vocabulario de las dos lenguas toscana y castellana, Sevilla, Francisco de Aguilar.

DE' MARCHI, Francesco (1810): Architettura militare di Francesco de' Marchi, Roma, Mariano de Romanise e Figli. 
Du CAnge, Ch. Du Fresne, Señor, con G. A. L. Henschel, P. CARPentier y L. Favre (1883-1887): Glossarium mediae et Infimae latinitatis (GMIL), Niort, L. Fevre.

FRANQUELO, Ramón (1862): La reina en Málaga: descripción de los arcos de triunfo monumentos, adornos y vistas más notables que ha habido en Málaga y en el límite de su provincia durante la estancia en ellas de S.M. la reina Doña Isabel II y su Real familia en octubre de 1862, Málaga, Imprenta del Correo de Andalucía.

GARCÍA ARIAS, José Luis (2015): Diccionario general de la lengua asturiana, Uvieu, Prensa Asturiana.

García CuAdRADO, Mercedes (1993): Las Cantigas: El códice de Florencia, Murcia, Universidad de Murcia.

GIL y CARRASCO, Enrique (1844), El Señor de Bembibre, Madrid, P. Mellado Ed.

GODEFROY, Frederic (1881-1902): Dictionnaire de l'ancienne langue française et de tous ses dialectes du $I X^{e}$ au $X V^{e}$ siècle, Paris, Bouillon.

GonZÁlez SimAnCAS, Manuel (1925): España Militar a principios de la Baja Edad Media, Madrid, Talleres del Depósito de la Guerra.

GUTIÉRREZ, Ramón (2005): Fortificaciones en Iberoamérica, Madrid, Fundación Iberdrola.

HARRIS, Cyril M., ed. (1977): Illustrated Dictionnary of Historic Architecture, New York, Dover Publications.

HONNORAT, Simon-Jude (1817): Dictionnaire provençal-français ou dictionnaire de la Langue d'Oc, ancienne et moderne, suivi d'un vocabulaire français-provençal, Digne, Repos.

HugO, Victor (1836): Obras de Victor Hugo, III, Madrid, ImprentaTomás Jordán.

IsTITUTO DELL'ENCICLOPEDIA ITALIANA (2015): Vocabolario Treccani (Treccani) [En línea: http://www.treccani.it/vocabolario].

LE PRESTE, S., SEÑOR De VAUBAN (1743): Tratado de la defensa de las plazas que escribió Mr. de Vauban, mariscal de Francia y director general de las fortificaciones de aquel reino, trad. de Ignacio de Sala, Cádiz, Imprenta de Pedro Gómez de Requena.

MÁRTIR De Anglería, Pedro (1944): Décadas del nuevo mundo, Buenos Aires, Editorial Bajel (reimpr. Valladolid, Maxtor, 2012).

MenÉnDeZ PidAL, Gonzalo (1986): La España del s. XIII leída en imágenes, Madrid, Real Academia de la Historia.

Morala, Rodríguez, José Ramón (2013): Corpus Léxico de Inventarios (CorLexIn), Madrid, RAE. < http://web.frl.es/CORLEXIN.html >.

Ortiz LanZ, José Enrique (1996): Piedras ante el mar: las fortificaciones de Campeche, Campeche, Gobierno del Estado de Campeche.

PALENCIA, Alfonso de (1967): Universal vocabulario en latín y en romance, facsímil de la edición de Sevilla, 1490, Madrid, Comisión Permanente de la Asociación de Academias de la Lengua Española.

PICOCHE, Jean-Louis (1972): Un romantique espagnol: Enrique Gil y Carrasco (1815-1846), Paris, Universidad de París IV.

PIÑA CHAN, Román (1977): Campeche durante el periodo colonial, México, SEP-INAH.

PRÓSPERI, Félix (1744): La gran defensa: nuevo método de fortificación, México, Hogal.

RAMÉE, Daniel (1868): Dictionnaire Général des termes d'architecture: en français, allemand, anglais et italien, Paris, Reinwald.

Real ACADEMia Española: Banco de datos (CORDE), Corpus diacrónico del español, [en línea, http://www.rae.es] [10/05/2015]. 
REAL ACADEMIA ESPAÑola (1726-1739): Diccionario de la lengua castellana, en que se explica el verdadero sentido de las voces, su naturaleza y calidad, con las phrases o modos de hablar, los proverbios o refranes, y otras cosas convenientes al uso de la lengua $[\ldots](D A)$, Madrid, Imprenta de Francisco del Hierro [en línea http://web.frl.es/DA.html].

Real ACADEmia EsPañola (2015): Nuevo Tesoro Lexicográfico de la Lengua Española (NTLLE) [en línea: http://ntlle.rae.es].

REAL ACADEMIA ESPAÑola (2014): Diccionario de la lengua castellana (DRAE) [en línea, http://www.rae.es].

REPOSSI, Cesare, dir. (1901): Bolletino della Societá pavese di storia patria. Vol. I, Pavia, Societá Pavese.

RoccA, Pietro (1871): Pesi e misure antiche di Genova e del Genovesato, Genova, Tip. Instituto Sordo-Muti.

RUIZ, Juan (1974): Libro de buen amor, edición de Jacques Joset, Madrid, Espasa Calpe.

RUIZ, Juan (1992): Libro de buen amor, edición de Alberto Blecua, Madrid, Cátedra.

SÁNCHEZ ORENSE, Marta (2012): La fortificación y el arte militar en los tratados renacentistas en lengua castellana: estudio lexicológico y lexicográfico, Salamanca, Universidad de Salamanca [Tesis doctoral].

SANCHO RAYÓN, José León (1840): Colección de documentos inéditos para la historia de España, volumen 13, Madrid, Imprenta de la Viuda de Calero.

ScotT, Walter (1812): The Minstrelsy of the Scottish Border: Consisting of Historical and Romantic Ballads, Collected in the Southern Counties of Scotland; With a Few of Modern Date, Founded Upon Local Tradition, Edinburgh, James Ballantyne, $5^{\text {a }}$ ed.

SCOTT, Walter (1825): Ivanhoe, trad. de José Joaquín de Mora, London, Rudolph Ackermann (Edición Traductológica Digital de Marcos Rodríguez Espinosa, Málaga, Universidad de Málaga, Proyecto de Investigación del MEC, 2004).

ScotT, Walter (1835): Ivanhoe ou le retour du croisé, en Ouevres de W. Scott, t. VIII [trad. A. J. B Defaucompret], Paris, Furne, Gosselin, Perrotin.

ScotT, Walter (1831): Ivanhoe, Boston, Samuel H. Parker.

Steuvechius, Godescalcus (1583): Brief van Godescalcus Steuvechius aan Christophe Plantin (ca. 1520-1589), Leiden, Universidad de Leiden.

TERRADAS, Esteban (1946): Neologismos, arcaísmos y sinónimos en plática de ingenieros, Madrid, S. Aguirre [Discurso de ingreso a la Real Academia Española].

TERrERos, Esteban (1786): Diccionario castellano con las voces de las Ciencias y de las Artes, Madrid, Imprenta de la Viuda de Ibarra, Hijos y Compañía.

VERGARA MARTín, Gabriel María (1921): Materiales para la formación de un vocabulario de palabras usadas en Segovia y su tierra, Madrid, Librería de los Sucesores de Hernando.

VILLENA, Leonardo (1971): "Glosario de términos castellológicos medievales en lenguas románicas», Castillos de España. Segunda época, 4, pp. 77-92.

VILLENA, Leonardo (1988): «Sobre las defensas verticales en España: tipología y terminología comparadas», en Andrés Bazzana, coord., Castrum 3. Guerre, fortification et habitat dans le monde méditerranéen au Moyen Age, Madrid, Casa de Velázquez-École Français de Rome, pp. 107-112.

VIOLLET LE DUC, Eugène (1854-1868): Dictionaire raisonné de l'architecture française du $X I^{\mathrm{e}}$ au $X V I^{\mathrm{e}}$ siècle, Paris, Ed. Bance-Morel. 


\section{TíTULO}

«Los imaginarios matacanes del castillo de Cornatel en El Señor de Bembibre de Gil y Carrasco. Estudio lexicográfico en torno a los términos matacán, matacaspas y sa[b]ratana»

«Imaginary matacanes in the castle of Cornatel in El Señor de Bembibre by Gil y Carrasco. Lexicographic study about the terms matacán, matacaspas and $\mathrm{sa}[\mathrm{b}]$ ratana»

Fecha de recepción: 17/03/2016 Fecha de aceptación: 09/12/2016

Resumen: En este artículo hemos estudiado el término matacaspas que aparece en el cap. 26 de la obra de Enrique Gil y Carrasco El Señor de Bembibre (1844) y que ha suscitado comprensibles dudas en los editores de la obra, siendo enmendado con frecuencia por matacanes. Nuestro objetivo era averiguar la propiedad del uso de la voz y para ello hemos estudiado el contexto y acudido a sus fuentes literarias y hemos recogido documentación lexicográfica acerca del uso del término en la literatura especializada, en base a lo cual podemos afirmar que la aparición en la obra de Gil y Carrasco de la voz estaría legitimada. Asimismo hemos querido arrojar luz sobre el origen, la etimología, las variantes y acepciones que han cobrado diversas voces relacionadas con el término matacán.

Palabras clave: Enrique Gil y Carrasco, El Señor de Bembibre, Terminología de arquitectura medieval defensiva, Matacán, Matacaspas, Sa[b]ratana.

Abstract: In this article we have studied the term matacaspas that has interested us by its appearance in the cap. 26 of the work of Enrique Gil and Carrasco El Señor de Bembibre (1844) and that has raised understandable doubts among the editors of this work, being frequently amended by matacanes. Our objective was to find out the correct use of the voice and therefore we have studied the context and verified its literary sources. We have collected lexicographic documentation about the use of the term in the specialized literature, which leads us to affirm that the appearance of this term in the work of Gil and Carrasco must be legitimized. We also want to shed light on the origin, etymology, variants and meanings that have taken other various words related with the term matacán.

Key words: Enrique Gil y Carrasco, El Señor de Bembibre, Defensive medieval architecture terminology, Matacán, Matacaspa, Saratana. 